\title{
Compound-specific chlorine isotope analysis of the herbicides atrazine, acetochlor and metolachlor
}

\author{
Violaine Ponsin ${ }^{1 *^{* *}}$, Clara Torrentó ${ }^{1 \dagger}$, Christina Lihl ${ }^{2}$, Martin Elsner ${ }^{2,3}$, Daniel Hunkeler ${ }^{1}$ \\ ${ }^{1}$ Centre of Hydrogeology and Geothermics (CHYN), University of Neuchâtel, 2000 Neuchâtel, Switzerland \\ ${ }^{2}$ Helmholtz Zentrum München, Institute of Groundwater Ecology, 85764 Neuherberg, Germany \\ ${ }^{3}$ Technical University of Munich, Chair of Analytical Chemistry and Water Chemistry, 81377 Munich, Germany
}

\begin{abstract}
A gas chromatography-single quadrupole mass spectrometry method was developed and validated for compoundspecific chlorine isotope analysis (Cl-CSIA) of three chlorinated herbicides, atrazine, acetochlor and metolachlor, which are widespread contaminants in the environment. For each compound, the two most abundant ions containing chlorine (202/200 for atrazine, 225/223 for acetochlor and 240/238 for metolachlor) and a dwell time of $30 \mathrm{~ms}$ were determined as optimized MS parameters. A Limit of Precise Isotope Analysis for ethyl acetate solutions of $10 \mathrm{mg} / \mathrm{L}$ atrazine, $10 \mathrm{mg} / \mathrm{L}$ acetochlor and $5 \mathrm{mg} / \mathrm{L}$ metolachlor could be reached with an associated uncertainty between 0.5 and $1 \%$. To this end, samples were measured tenfold and bracketed with two calibration standards which covered a wide range of $\delta^{37} \mathrm{Cl}$ values and whose amplitudes matched those of the samples within $20 \%$ tolerance. The method was applied to investigate chlorine isotope fractionation during alkaline hydrolysis of metolachlor, which showed a shift in $\delta^{37} \mathrm{Cl}$ of $+46 \%$ after $98 \%$ degradation, demonstrating that chlorine isotope fractionation could be a sensitive indicator of transformation processes even when limited degradation occurs. This method, combined with large-volume solid-phase extraction (SPE), allowed application of Cl-CSIA to environmentally relevant concentrations of widespread herbicides (i.e. 0.5 to $5 \mu \mathrm{g} / \mathrm{L}$ in water before extraction). Therefore, the combination of large-volume SPE and Cl-CSIA is a promising tool for assessing the transformation processes of these pollutants in the environment.
\end{abstract}

Chlorine-containing pesticides (e.g. chlorotriazines, chloroacetanilides, aromatic acid herbicides, organochlorine pesticides and some pyridazinones and pyridines) are frequently found in water bodies worldwide following their use in agriculture. ${ }^{1-3}$ Sixteen of them are included in the current Priority Substances list under the EU Water Framework Directive (2000/60/EC). However, little is known about their transformation in soils and water. Many transformation pathways involve breaking of carbon-chlorine bonds, similarly to chlorinated organic legacy compounds. ${ }^{4}$ Chlorine Compound-Specific Isotope Analysis (CSIA) is a particularly promising approach to gain insight into their fate. CSIA relies on kinetic isotope effects resulting from the differences in degradation rates of molecules containing light or heavy isotopes in the reactive position. This leads to changes in the isotope ratio of the contaminant fraction that has not yet been degraded. Whereas C-CSIA methods are available for many chlorinated organic legacy compounds and even for some chlorine-containing pesticides ${ }^{5-9}$, analytical methods for $\mathrm{Cl}-$ CSIA are so far only available for a narrow range of compounds, especially short chain polychlorinated aliphatic hydrocarbons. ${ }^{10,11}$

This limited availability is explained by numerous analytical challenges associated with Cl-CSIA. Offline methods - such as dual inlet isotope ratio mass spectrometry (DI-IRMS) after conversion to $\mathrm{CH}_{3} \mathrm{Cl}$, fast atom bombardment IRMS (FABIRMS) after conversion to $\mathrm{AgCl}$ and thermal ionization mass spectrometry (TIMS) after conversion to $\mathrm{CsCl}$ - require time intensive preparation procedures with multiple steps and relatively large sample amounts. ${ }^{12}$ These techniques have been used for measuring ${ }^{37} \mathrm{Cl}$ signatures of commercial and pure samples of pesticides, but they are not suitable for online coupling to a chromatograph. ${ }^{13-19}$ Chlorine isotope ratios can also be measured by gas chromatography (GC)-continuous flow (CF)-IRMS, although this method is costly since specialized IRMS instruments with a modified layout of ion detectors are required. ${ }^{12}$ Furthermore, GC-CF-IRMS is restricted to analysis of certain compounds and molecular fragments by the fixed Faraday detector arrangement and modest mass range, which limits its applicability to pesticides. Recently, Renpenning et $\mathrm{al}^{20}$ developed an online method using GC interfaced with multiple-collector inductively coupled plasma MS (GC-MCICPMS) for measuring ${ }^{37} \mathrm{Cl}$ signatures in semi-volatile compounds. This method requires, however, expensive equipment that is only present in a limited number of specialized laboratories. Although this fact limits its application for routine analysis, GC-MC-ICPMS is a good alternative for calibrating compound-specific in-house working standards against the international reference standards. ${ }^{21,22}$

An alternative low-cost approach for $\mathrm{Cl}$ isotope ratio analysis is GC-single quadrupole MS (GC-qMS). This approach has been applied to different classes of chlorinated compounds, such as chlorinated ethenes, methanes and ethanes ${ }^{11,23-25}$ and is available to many laboratories.

The purpose of this work is to expand Cl-CSIA to widely-used chlorinated herbicides, which is a class of compounds with a particularly high environmental relevance as explained above. Compared to polychlorinated hydrocarbons, they are characterized by a larger carbon number and often only one 
chlorine atom, which makes chlorine a particularly attractive indicator for transformations involving carbon-chlorine bonds, as the isotope effect is not diluted by other chlorine atoms at non-reacting positions. Online Cl-CSIA of polychlorinated aliphatic hydrocarbons can be performed by introducing fragments and molecules ions in either IRMS or qMS. For chlorinated herbicides, however, ions exceed the typical mass range of IRMS instruments. Therefore, qMS is the only option. Aeppli et al. ${ }^{25}$ measured chlorine isotope ratios of the insecticides DDT and pentachlorophenol, both containing 5 chlorine atoms, using GC-qMS. The goal of this study is to expand Cl-CSIA to large molecules bearing only one chlorine atom, for which chlorine isotopes are expected to be a very sensitive indicator for transformations involving carbonchlorine bonds. Several analytical challenges are associated to the application of a GC-qMS method to such compounds. While chlorine atoms contribute to $\sim 50-95 \%$ of the total mass of previously measured polychlorinated compounds, they account to only $\sim 10-15 \%$ for mono-chlorinated herbicides. This fact, together with the low environmental concentrations represent a challenge for Cl-CSIA of these contaminants. The feasibility of reliable (i.e. with sufficient precision and sensitivity) GC-qMS measurements of those compounds with a high number of carbon atoms but one chlorine atoms has therefore to be tested. A higher influence of interfering non-target fragments containing two ${ }^{13} \mathrm{C}$ atoms is also expected, and thus further correction may be necessary. ${ }^{25}$ Furthermore, proper standardization and correction procedures need to be defined for these compounds. It has been shown for chlorinated volatile organic compounds that samples have to be bracketed with two references of the exact identical molecular structure with different isotope ratios. These isotope ratios need to cover the measurement range to minimize distortion relative to the SMOC scale and to account for potentially variable calibration slopes for the same instrument over time. ${ }^{11,26,27}$ Finally, it needs to be demonstrated that, in combination with large-volume solid-phase extraction $(\mathrm{SPE})^{28}$, environmentally relevant concentrations can indeed be reached, which would open a route for analyzing the compounds at environmentally relevant levels with potentially large benefits for understanding the longterm fate of these compounds.

As such model herbicides that bear one chlorine but numerous carbon atoms, challenging Cl-CSIA at environmental concentrations, we selected three of the most frequently detected contaminants in groundwater: atrazine (ATR), acetochlor (ACETO) and metolachlor (METO) (Table S1, Supporting Information, SI). Metolachlor and acetochlor are among the most frequently applied herbicides in North America and the European Union ${ }^{29-31}$ while ATR is still present in aquifers although its commercial use was banned in the EU in 2003. Concentrations of these herbicides, and their metabolites frequently exceed the EU drinking water (Directive 98/83/EC) and groundwater quality (Directive 2006/118/EC) standards of $0.1 \mu \mathrm{g} / \mathrm{L}$ for individual pesticides and relevant degradation products $(0.5 \mu \mathrm{g} / \mathrm{L}$ for total pesticides $) .{ }^{1,3,32,33}$

The objective of this work was therefore to develop a routine, cost-efficient and universal online GC-qMS method for $\mathrm{Cl}$ CSIA of ATR, ACETO and METO as frequently detected chlorinated herbicides. We determined MS parameters, and performances of the optimized method using referenced material with independently determined isotope ratios. As any isotope method, the method requires rigorously characterized reference material, which was developed in another study. ${ }^{21}$ The method was tested on samples from a degradation experiment. Furthermore, the optimized method was coupled with the SPE method we recently developed ${ }^{28}$ and the whole SPE-Cl-CSIA method was validated using large volume environmental water samples spiked with the target herbicides. This study therefore presents a benchmark for routine application of Cl-CSIA of micropollutants bearing numerous carbon atoms and only one $\mathrm{Cl}$, which opens new possibilities for its application to newer classes of contaminants.

Table 1. Suppliers and isotope ratios of ATR, ACETO and METO standards used for method development. $\delta^{37} \mathrm{Cl}$ values normalized to the SMOC scale were determined by GC-MC-ICPMS. ${ }^{21} \delta^{13} \mathrm{C}$ values were determined either through injection in an EA-IRMS ${ }^{c}$ or through injection in a GC-IRMS ${ }^{d}$, together with standards already referenced by EA-IRMS, as explained

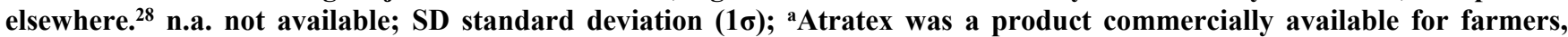
containing ATR as the active ingredient; ${ }^{b} \mathrm{Lihl}$ et al. ${ }^{21}$

\begin{tabular}{|c|c|c|c|c|c|}
\hline & Standard & Supplier & Purity [\%] & $\delta^{37} \mathrm{Cl} \pm \mathrm{SD}[\%$ ] & $\delta^{13} \mathrm{C} \pm \mathrm{SD}[\%$ ] \\
\hline \multirow{6}{*}{ Group 1} & ATR \#4 & Oskar Tropitzsch & n.a. & $-0.9 \pm 0.2^{b}$ & $-26.4 \pm 0.1^{c}$ \\
\hline & ATR \#11 & Riedel-de Haën & 99 & $3.6 \pm 0.4^{\mathrm{b}}$ & $-28.2 \pm 0.1$ \\
\hline & ACETO-I & Chemos & n.a. & $0.3 \pm 0.3^{b}$ & $-27.8 \pm 0.2^{\mathrm{d}}$ \\
\hline & ACETO-F & $\begin{array}{l}\text { produced by } \mathrm{SN}_{2} \text { reaction } \\
\text { with } \mathrm{NaN}_{3} \text { in acetone }{ }^{\mathrm{b}}\end{array}$ & n.a. & $18.5 \pm 0.2^{b}$ & $-16.4 \pm 0.2^{\mathrm{d}}$ \\
\hline & METO-I & Chemos & n.a. & $-4.3 \pm 0.2^{b}$ & $-28.6 \pm 0.1^{d}$ \\
\hline & METO-F & $\begin{array}{l}\text { produced by } \mathrm{SN}_{2} \text { reaction } \\
\text { with } \mathrm{NaN}_{3} \text { in acetone }{ }^{\mathrm{b}}\end{array}$ & n.a. & $5.1 \pm 0.3^{b}$ & $-22.5 \pm 0.1^{\mathrm{d}}$ \\
\hline \multirow{5}{*}{ Group 2} & ATR_A & Oskar Tropitzsch & n.a. & $-0.9 \pm 0.1^{b}$ & $-28.6 \pm 0.1^{c}$ \\
\hline & Atratex $^{\mathrm{a}}$ & Leu + Gygax & 90 & $-1.5 \pm 0.3$ & $-30.4 \pm 0.2^{\mathrm{c}}$ \\
\hline & ACETO_A & Chemos & 96.3 & $-0.1 \pm 0.2^{b}$ & $-25.0 \pm 0.1^{\mathrm{c}}$ \\
\hline & METO_A & Oskar Tropitzsch & n.a. & $0.0 \pm 0.1^{\mathrm{b}}$ & $-30.4 \pm 0.1^{\mathrm{c}}$ \\
\hline & METO_B & Chemos & 96.2 & $-2.8 \pm 0.1^{b}$ & $-28.0 \pm 0.2^{\mathrm{d}}$ \\
\hline
\end{tabular}




\section{Experimental section}

Chemicals and reagents. Different reference compounds for ATR, ACETO and METO were used during this study. Details about suppliers, purity and isotope ratio are summarized in Table 1.

$1 \mathrm{mg} / \mathrm{mL}$ standard stock solutions were prepared in ethyl acetate (EtAc, analytical grade) and stored at $4{ }^{\circ} \mathrm{C}$ in the dark. Standards used for analysis were then prepared from a 100 or $250 \mathrm{mg} / \mathrm{L}$ daughter solution diluted in EtAc to a final concentration comprised between 2 and $40 \mathrm{mg} / \mathrm{L}$. All solutions were renewed every 6 months.

Chlorine Isotopes analysis by GC-qMS. Chlorine isotope ratios were determined using an Agilent 7890 A GC coupled to an Agilent $5975 \mathrm{qMS} .1 \mu \mathrm{L}$ of solution was injected splitless in a split/splitless injector maintained at $250{ }^{\circ} \mathrm{C}$. A DB- $17 \mathrm{~ms}$ column (30 m x $0.25 \mathrm{~mm}, 0.25 \mu \mathrm{m}$, Agilent $\mathrm{J} \& \mathrm{~W}$ ) operated in constant flow mode $(1.2 \mathrm{~mL} / \mathrm{min}$ of helium 6.0$)$ was used for separation. The oven program was $60{ }^{\circ} \mathrm{C}(1 \mathrm{~min}), 30^{\circ} \mathrm{C} / \mathrm{min}$ to $190{ }^{\circ} \mathrm{C}(3 \mathrm{~min}), 3{ }^{\circ} \mathrm{C} / \mathrm{min}$ to $210^{\circ} \mathrm{C}(3 \mathrm{~min})$. Total run time was $18 \mathrm{~min}$ and ATR eluted after $10.7 \mathrm{~min}$, ACETO after $12.5 \mathrm{~min}$ and METO after $14.5 \mathrm{~min}$. A chromatogram obtained after the injection of standards is shown in Figure S1 (SI). The interface was maintained at $280{ }^{\circ} \mathrm{C}$, the ion source at $230{ }^{\circ} \mathrm{C}$ and the quadrupole at $150{ }^{\circ} \mathrm{C}$. Selected-ion monitoring (SIM) measurements were performed. Optimum MS parameters (dwell time and $\mathrm{m} / \mathrm{z}$ monitored) were determined during method development. Output data were processed with ChemStation (Agilent) using the ChemStation integrator with default integration settings.

Calculations of chlorine isotope ratios. Figure S2 (SI) shows the mass spectra obtained in electron ionization mode for ATR, ACETO and METO respectively, including the most abundant fragments containing the chlorine atom (m/z 200, 202, 215 and 217 for ATR; m/z 223, 225, 224 and 226 for ACETO; $\mathrm{m} / \mathrm{z} 238$ and 240 for METO).

Chlorine isotope ratios were calculated considering the two most abundant ions of each fragment group, following the most abundant ions method. ${ }^{34}$ The modified multiple ion method ${ }^{35}$ was also tested. Detailed information about the different methods is given in the SI (section II.2). Briefly, when two ions were monitored, the isotope ratio was obtained from the ratio of the corresponding isotopologues according to Eq. 1.

$$
R={\frac{37}{{ }^{3} \mathrm{Cl}}}_{\text {method }}
$$

For the target herbicides,

$$
R(A T R)=\frac{{ }^{202} I}{200} ; \quad R(\text { ACETO })=\frac{{ }^{225} I}{223 I} ; R(\text { METO })=\frac{{ }^{240} I}{{ }^{238} I}
$$

where $I$ indicates the ion peak intensities.

Standardization and evaluation of uncertainty. The obtained isotope ratios were expressed in per mil (\%o) using the delta notation relative to an external standard, Eq. (3)

$$
\delta^{37} C l=\frac{R}{R_{\text {std }}}-1
$$

where $R$ and $R_{\text {std }}$ are the isotope ratios of the sample and the standard, respectively.
For GC-qMS, a higher number of repeats are necessary, typically 5 to 10 , to reach a sufficient precision. ${ }^{26}$ Ten injections of each sample were performed and two external working standards, also injected ten times each, were interspersed along the sequence to correct for potential drift. Instrument-specific $\delta^{37} \mathrm{Cl}$ values were determined by referencing averaged ratios versus one of the external working standards according to Eq. 3.

For conversion to delta values relative to the SMOC scale, a two-point calibration ${ }^{26}$ was used, by means of two external standards interspersed along the sequence. Instrument-specific values of the external standards were plotted against their values on the SMOC scale and sample measurements were subsequently evaluated using the intercept and the slope of this regression. The error of the slope of the calibration curve was calculated as $95 \%$ confidence interval.

The $\delta^{37} \mathrm{Cl}$ values on the international SMOC scale of the external standards were determined by GC-MC-ICPMS ${ }^{21}$ according to published procedure ${ }^{20,36}$ and are shown in Table 1. These values were obtained after two-point calibration to the SMOC. ${ }^{21}$ Atratex was analyzed on a different MC-ICPMS instrument, together with the other two ATR external standards (ATR\#4 and ATR\#11), which were used for a two-point normalization approach to obtain the final $\delta^{37} \mathrm{Cl}$ Atratex value.

A one-point calibration was used for the large-volume water samples spiked with ACETO, since only one standard (ACETO_A) was initially available. The following equation was used for one-point calibration ${ }^{25}$ :

$$
\delta^{37} C l=\left(\frac{R}{R_{s t d}}-1\right)+\delta^{37} C l_{s t d} \frac{R}{R_{s t d}}
$$

To take into account that several injections are performed for each sample and standard, uncertainty in $\delta^{37} \mathrm{Cl}$ measurements was reported as the standard error of the mean $\left(\sigma_{\mathrm{m}}\right)$, according to Eq. 5:

$$
\sigma_{m}=\frac{s}{\sqrt{n}}
$$

where $s$ is the sample standard deviation and $n$ is the number of injections performed (typically $n=10$ for samples and $n=20$ for standards). For comparison with previous studies using GCqMS for Cl-CSIA, the uncertainty was also reported as the standard deviation $(s=1 \sigma)$.

Evaluation of method performance. Precision, trueness, the linearity range of the method and the Limit for Precise Isotope Analysis (LPIA) are useful metrics to evaluate the performance of CSIA methods. Precision was reported as $\pm \sigma_{\mathrm{m}}$ for $n$ measurements. Trueness $(\Delta \delta)$ was evaluated for the whole SPECl-CSIA method (see method application section) and expressed as the offset between the isotope signature measured by GC-qMS and the target value, which is the reference isotope signature determined by GC-MC-ICPMS (Table 1). For isotope measurements, the linearity range is the range between the smallest and the largest amount on column (i.e. signal intensity) for which the uncertainty of the mean measured isotope ratio is within a predefined uncertainty interval. LPIA for each target compound was determined according to the moving mean $\operatorname{method}^{37}$, using standard solutions of known isotope composition and predefined $\sigma_{\mathrm{m}}$. The pairs of external standards covering a wide range of $\delta^{37} \mathrm{Cl}$ values were used to evaluate these different metrics (group 1 in Table 1). 
Correction for ${ }^{13} \mathrm{C}$. Fragments containing two ${ }^{13} \mathrm{C}$ and one ${ }^{35} \mathrm{Cl}$ have the same mass as fragments with only ${ }^{12} \mathrm{C}$ and one ${ }^{37} \mathrm{Cl}$ (target fragment), and can therefore interfere during measurements. This effect has to be considered to avoid a bias in the measurement. A correction has been proposed by Aeppli et al. ${ }^{25}$ based on the carbon isotopic composition of the sample, as follows, Eq. (6):

$$
R_{C l}^{c o r r}=R_{C l}-\frac{1}{n_{C l}} \times \frac{n_{C}\left(n_{C}-1\right)}{2} \times R_{C}^{2}
$$

where $n_{C l}$ and $n_{C}$ are the number of chlorine and carbon atoms per fragment and $R_{C l}$ and $R_{C}$ are the measured chlorine and carbon isotope ratio, respectively. This correction can be applied if the carbon isotopic compositions of samples and standards are known. If the latter is unknown, it is still possible to estimate the associated uncertainty. ${ }^{25}$

Since the probability of occurrence of other interfering isotopologues containing one ${ }^{13} \mathrm{C}$ and one ${ }^{15} \mathrm{~N}$ or containing one ${ }^{18} \mathrm{O}$ is very small (Table $\mathrm{S} 2, \mathrm{SI}$ ), corrections for $\mathrm{N}$ and $\mathrm{O}$ are expected to be negligible and were, therefore, not assessed.

Method application: spiked large-volume water samples and hydrolysis experiment. As a proof of principle, the method was applied to i) large volume environmental water samples that were spiked with ATR, ACETO and METO to make sure that SPE does not induce isotope fractionation and thus to validate the whole SPE-Cl-CSIA method and, ii) an alkaline hydrolysis experiment of METO to test the method over a wide range of $\delta$ values. Note that only group 2 of external standards was available when these two method applications were performed.

Spiked large-volume water samples. $10 \mathrm{~L}$ samples of drainage water were spiked with standards of ATR, ACETO and METO with known isotope signatures at 0.5 to $5 \mu \mathrm{g} / \mathrm{L}$ and SPE was performed, as explained by Torrentó et al. ${ }^{28}$ For Cl-CSIA, standards were interspersed within the sequences and the twopoint calibration approach was used for normalizing $\delta^{37} \mathrm{Cl}$ raw values to the SMOC scale, except for ACETO, for which the one-point calibration approach was used since only one external standard was available at that time.

Hydrolysis experiment. The hydrolysis reaction was performed in a solution buffered at $\mathrm{pH} 12\left(0.05 \mathrm{M} \mathrm{Na}_{2} \mathrm{HPO}_{4}\right.$ with $0.1 \mathrm{M}$
$\mathrm{NaOH}$ ), in the dark. Initial METO concentration was $50 \mathrm{mg} / \mathrm{L}$ in $200 \mathrm{~mL}$ flasks that were stored at $60{ }^{\circ} \mathrm{C}$. Five milliliter aliquots were sampled at regular intervals and the reaction was stopped by adding $20 \mu \mathrm{L}$ of a $40 \% \mathrm{HNO}_{3}$ solution to obtain a circumneutral $\mathrm{pH}$. METO concentrations were determined by ultra-high pressure liquid chromatography quadrupole time of flight mass spectrometry following a method described elsewhere. ${ }^{28}$ Before isotope analyses, the $5 \mathrm{~mL}$-aliquots were extracted by SPE, following a method modified from Torrentó et al. ${ }^{28}$ Details of the SPE method, as well as the results of its validation for Cl-CSIA, can be found in the SI (Section II.3). Carbon isotope ratios in the extracts were measured by GCIRMS, as explained elsewhere. ${ }^{28}$ Chlorine isotope ratios were measured with the optimized method, using the two-point calibration approach and applying corrections to take into account fragments with two ${ }^{13} \mathrm{C}$ atoms.

The chlorine and carbon isotope fractionations $\left(\varepsilon_{\mathrm{Cl}}\right.$ and $\left.\varepsilon_{\mathrm{C}}\right)$ were determined according to the Rayleigh equation ${ }^{38}$ :

$$
\ln \left(\frac{\delta+1}{\delta_{0}+1}\right)=\varepsilon \times \ln f
$$

where $\delta_{0}$ and $\delta$ are the isotope values at the beginning of the reaction and at any time $\mathrm{t}$, respectively, and $f$ is the remaining fraction of substrate at time $t$.

For both the SPE samples and hydrolysis samples, the total uncertainty had to be calculated taking into account uncertainties associated with sample measurement but also with the measurement of the two standards. Details about the procedure that was followed are provided in the SI (Section II.5).

\section{Results and Discussion}

Optimization of MS parameters. We tested different ion pairs and different dwell times (2, and 4 ions and dwell times between 30 and $100 \mathrm{~ms}$ ). The following ions were tested: for ATR, the two most abundant (m/z 200 and 202), the pair m/z 215 and 217, and the four of them; for ACETO, the two most abundant (m/z 223 and 225), the pair $\mathrm{m} / \mathrm{z} 224$ and 222 and the four of them; for METO, only the two most abundant (m/z 238 and 240 ), as $\mathrm{m} / \mathrm{z} 211$ and 213 have very low abundance (Figure S2, SI).

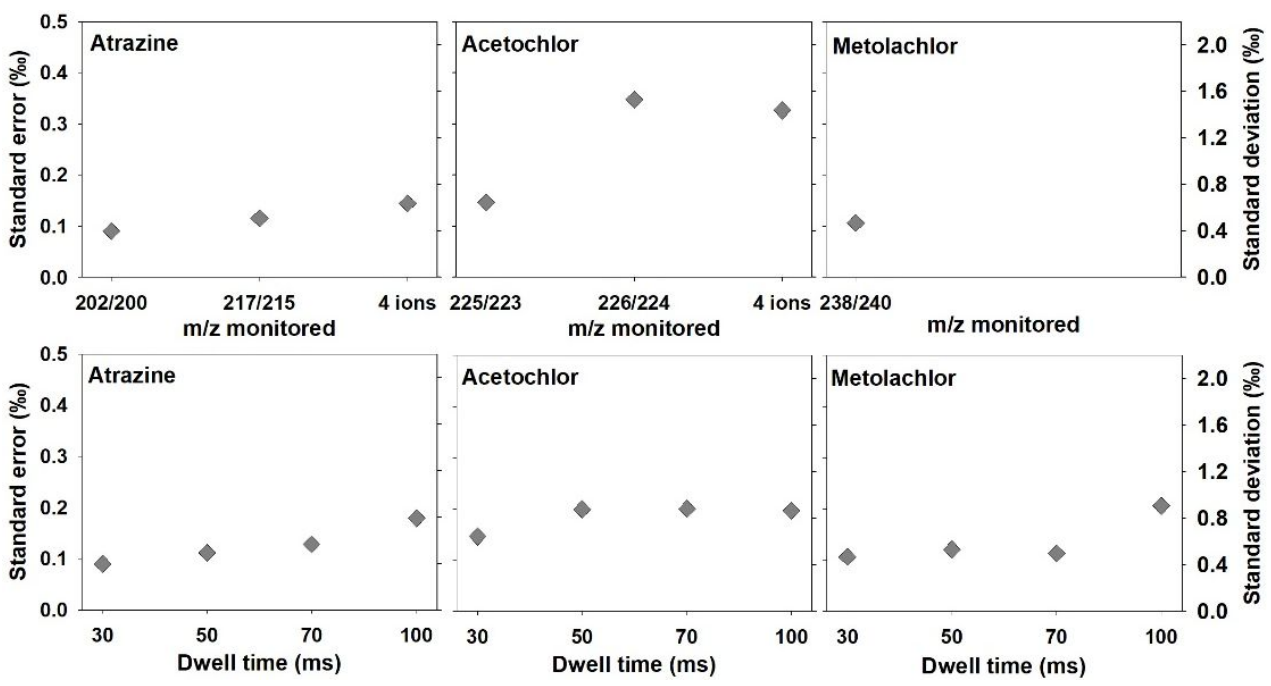

Figure 1. Upper panels: $\sigma_{\mathrm{m}}$ of isotope ratio as a function of $\mathrm{m} / \mathrm{z}$ monitored for ATR, ACETO, and METO (dwell time of $30 \mathrm{~ms}$ ). Note that for METO, only one pair of ions was tested. Lower panels: $\sigma_{\mathrm{m}}$ of isotope ratio as a function of dwell time for ATR (m/z 202/200), ACETO (m/z 225/223), and METO (m/z 240/238). Note that one point corresponds to one sequence ( $\mathrm{n}=20$ injections of standards; $10 \mathrm{ng}$ on column for ATR and METO, $30 \mathrm{ng}$ for ACETO). Standard deviation $(1 \sigma)$ is also shown. 
For each configuration, 20 injections of standards at $10 \mathrm{mg} / \mathrm{L}$ for ATR and METO and $30 \mathrm{mg} / \mathrm{L}$ for ACETO were done and $\sigma_{\mathrm{m}}$ for each tested configuration is shown in Figure 1. For the three compounds, the configuration that gave the most precise results was the one recording the two most abundant ions (202 and 200 for ATR, 225 and 223 for ACETO and 240 and 238 for METO) with a dwell time of $30 \mathrm{~ms}$. This configuration resulted in $\sigma_{\mathrm{m}}$ below $0.16 \%$ for the three analytes, which corresponds to $1 \sigma$ of $0.7 \%$ for $n=20$. For chlorinated solvents, previous studies have shown that the most abundant ions method is the best choice for compounds with three or more chlorine atoms (trichloroethylene -TCE-, perchloroethylene -PCE-, chloroform $-\mathrm{CF}$ - and carbon tetrachloride $-\mathrm{CT}-$ ), but not for compounds with two chlorine atoms (cis-dichloroethylene cDCE-), for which more precise results are obtained using the modified multiple ion method. ${ }^{11,35}$ For the target herbicides, with one chlorine atom, best results were obtained recording the two most abundant ions. For ATR, our results are consistent with the theoretical work of Sakaguchi-Söder ${ }^{24}$, who, using stochastic analysis, selected the fragment ions at $\mathrm{m} / \mathrm{z}=200$ and 202 as the most appropriate for Cl-CSIA for ATR.

Method performance. To determine the precision and linearity range of the method, standard solutions in EtAc of the three compounds of known isotope composition (Table 1) were analyzed using the optimized MS configuration for injected amounts in the range of 5 to $30 \mathrm{ng}$ analyte (corresponding to 0.02-0.14 nmol Cl). Two external working standards (two-point calibration approach) were injected and two different methods were compared to determine instrument-specific $\delta^{37} \mathrm{Cl}$ values of one of the standard taken as a sample: referencing to averaged ratios of the other standard at i) each concentration (i.e., adjusting samples and standards to the same concentration) or at ii) $10 \mathrm{ng}$ analyte (i.e., constant standard concentration).

We observed that when the concentration of the standards is adapted to the sample concentration, precision, but not trueness (i.e. offset from the target value $)^{11}$, is amount-dependent for the three analytes, whereas when the concentration of the standards is held constant along the sequence, both sample precision and trueness are amount-dependent (Figure 2). Therefore, for the three herbicides, concentrations of external standards have to be adjusted to sample concentrations for accurate chlorine isotope analysis. A tolerance of $20 \%$ around the target concentration was determined, i.e. isotope ratios are still consistent when the concentration of samples is within $20 \%$ around the concentration of standards. Previous studies for chlorinated volatile organic compounds showed that to obtain accurate chlorine isotope analysis by GC-qMS, it is critical, for $\mathrm{TCE}^{25}$, but not for chlorinated methanes ${ }^{11}$, to inject the isotopic standard at a similar concentration as the samples. Heckel et al. ${ }^{11}$ suggested that chlorine isotope values are amountindependent when fragmentation leads to a predominant (chlorine atom-containing) fragment (such as for CF and CT), whereas amount dependency occurs when several fragments of similar intensity are formed (such as for TCE). We observe a similar relationship for our analytes: ACETO and ATR do not have predominant fragments (Fig. S2, SI) and show a higher amount-dependency, while METO has more predominant fragments and a lower amount-dependency (Figure 2).

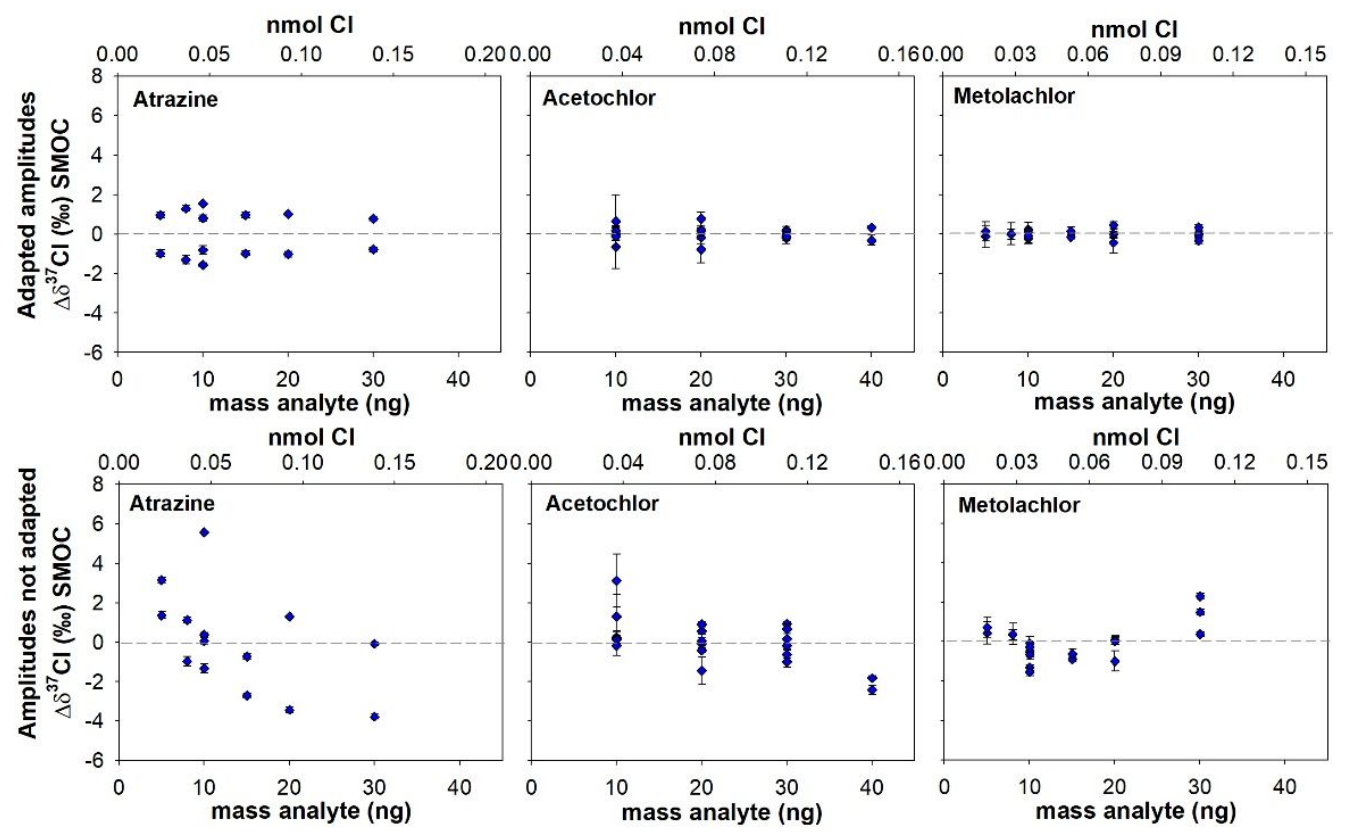

Figure 2. Precision and trueness of chlorine isotope measurements as a function of the mass of analyte injected for ATR, ACETO and METO with (upper panels) and without (lower panels) adapting amplitudes to the amplitude of the samples. For each point, $n=10$ injections. Error bars show $\sigma_{\mathrm{m}}$ for each 10 injections. The horizontal bars represent the reference isotope signatures determined by GC-MC-ICPMS $\left(\Delta \delta^{37} \mathrm{Cl}\right.$ $=0$ ). Note that each panel corresponds to the results of two (ATR) or three (ACETO and METO) sequences, each with $n=20$ for each concentration level.

For isotope measurements, the LPIA is a tradeoff between a low amount of compound injected and a high precision. Depending on the objective of the study, a high precision or a low detection limit might be the priority. For that reason, we determined the LPIA for two different uncertainties $\left(\sigma_{\mathrm{m}}\right), 0.5$ and $1 \%$. For $\sigma_{\mathrm{m}}$ of $0.5 \%$, the LPIA was $10 \mathrm{mg} / \mathrm{L}$ (10 $\mathrm{ng}$ compound on-column 
or $0.04 \mathrm{nmol} \mathrm{Cl}$ ) for ACETO and $5 \mathrm{mg} / \mathrm{L}$ (5 ng compound, 0.02 $\mathrm{nmol} \mathrm{Cl}$ ) for METO (Fig. S5, SI). For $\sigma_{\mathrm{m}}$ of $1 \%$, the same LPIA was obtained for ACETO, whereas the LPIA for METO was 2 $\mathrm{mg} / \mathrm{L}$ ( $2 \mathrm{ng}$ compound, $0.01 \mathrm{nmol} \mathrm{Cl}$ ). For ATR, only $\sigma_{\mathrm{m}}$ of $1 \%$ could be reached with our data, with a LPIA of $10 \mathrm{mg} / \mathrm{L}$ (10 ng compound on-column or $0.05 \mathrm{nmol} \mathrm{Cl}$ ). At the conditions described above and with adapted amplitudes (Fig. 2), the linearity range for a $\sigma_{\mathrm{m}}$ of $1 \%$ was between 10 and $30 \mathrm{mg} / \mathrm{L}$ for ATR, 10 and $40 \mathrm{mg} / \mathrm{L}$ for ACETO and 5 and $30 \mathrm{mg} / \mathrm{L}$ for METO.

The slopes obtained for the two-point calibration to the SMOC scale are shown in Figure 3. For each sequence, values measured for the external standards were plotted against their values on the SMOC scale and the slope of this regression was determined. For ATR, slopes ranged between 0.58 and 1.69 (average of 1.05 \pm 0.23 ) in 34 different measurement sequences within a six-month period. For ACETO, 38 sequences within 9 months resulted in calibration slopes between 0.90 and 1.05 (average of $0.97 \pm 0.03$ ). Calibration slopes for METO ranged from 0.94 to 1.18 (average of $1.07 \pm 0.05$ ) in 59 different measurement sequences within a 13 -month period. Variations in instrument conditions, i.e. before or after source cleaning and with or without new filaments show little to no influence on the value and stability of the slopes measured, and no overtime drift was observed.

Results for ATR are not as good as for chloroacetanilide herbicides, with slopes showing more variations from one sequence to the other. This can be explained by the overall higher uncertainty for ATR measurements, associated with standards for ATR that are only 4.5\% apart, whereas for ACETO and METO the two standards are $18.3 \%$ and $9.4 \%$ apart, respectively. This effect is shown for METO in Figure S6 (SI). The calibration slope is more stable and closer to unity using the two standards further apart on the SMOC scale $\left(\Delta \delta^{37} \mathrm{Cl}=9.40 \%\right)$ than using the two standards that are only $2.74 \%$ apart. It is thus crucial to have a wide span in the $\delta^{37} \mathrm{Cl}$ values of the two calibration standards to obtain a reliable calibration slope for future measurements. After a GC maintenance, the ATR peak shape also tended to deteriorate faster than for the two other herbicides (tailing has been observed), which may hinder reliable isotope ratios and required regular column trimming and changes of the inlet liner. Calibration curves are thus target-analyte specific and may vary over time. This strongly emphasizes the need for calibration by two characterized compound-specific isotope standards for chlorine isotope measurements.

Correction for two ${ }^{13} \mathrm{C}$ atoms. $\mathrm{Cl}$ isotope data for $\mathrm{ATR}$, ACETO and METO were evaluated with and without correction to take into account fragments with two ${ }^{13} \mathrm{C}$ atoms. We assumed a maximum enrichment in ${ }^{13} \mathrm{C}$ of $+20 \%$, which would correspond to at least $96 \%$ of degradation based on previously published carbon fractionation $\left(\varepsilon_{\mathrm{C}}\right)$ for ATR, ACETO and METO degradation. ${ }^{5,39-45}$ Applying Eq. (6), we determined that an enrichment in ${ }^{13} \mathrm{C}$ of $+20 \%$ is associated with an offset between uncorrected and corrected $\mathrm{Cl}$ isotope value of $-0.22 \%$ o for ATR (fragment $\mathrm{m} / \mathrm{z}$ 202: one $\mathrm{Cl}$ atom and seven $\mathrm{C}$ atoms), $-0.93 \%$ for ACETO (fragment $\mathrm{m} / \mathrm{z} 225$ : one $\mathrm{Cl}$ and $12 \mathrm{C}$ ) and $1.02 \%$ for METO (fragment $\mathrm{m} / \mathrm{z} 240$ : one $\mathrm{Cl}$ and $13 \mathrm{C}$ ). Detailed estimations are provided in Table S3 (SI).

For ATR, the difference between corrected and uncorrected values is within the range of uncertainty of measurement and can be therefore ignored, provided that carbon isotope values do not exceed a $+20 \%$ enrichment. In this case, data should be evaluated to make sure that a correction could still be safely ignored. For ACETO and METO, although the overestimation of $\mathrm{Cl}$ delta values is limited, a correction should be applied as uncorrected values can lead to an overestimation of the fractionation associated with abiotic or biotic degradation. In many cases, carbon isotope data tend to be available as a dual or multiple-isotope approach is followed.
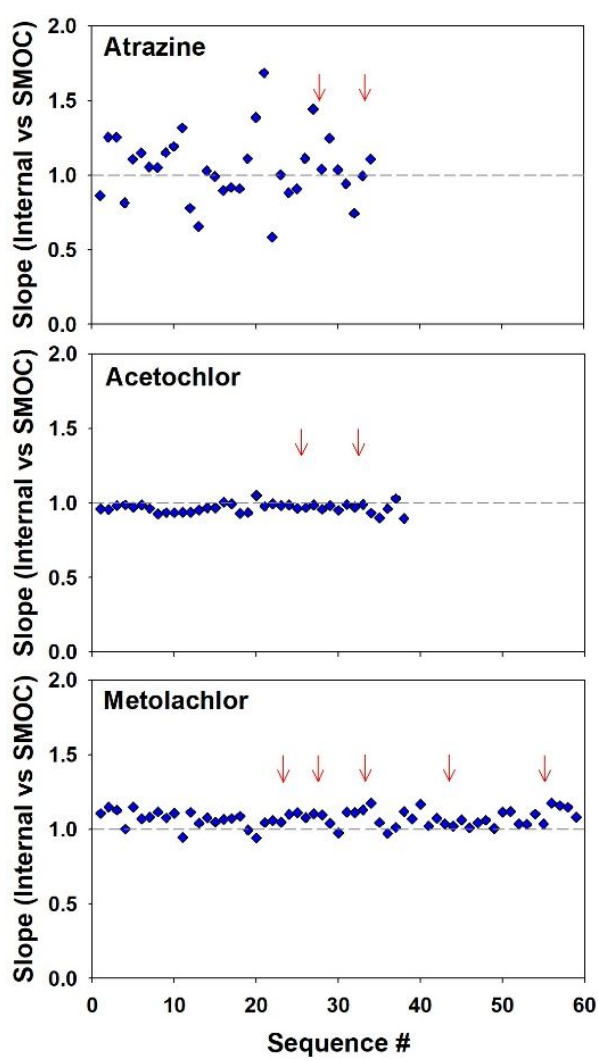

Figure 3. Calibration slope versus sequence number for ATR, ACETO, and METO. Arrows show changes of filaments and/or source cleaning. Injected concentrations ranged from 10 to $40 \mathrm{mg} / \mathrm{L}$ for ATR, 5 to $30 \mathrm{mg} / \mathrm{L}$ for ACETO and 5 to $45 \mathrm{mg} / \mathrm{L}$ for METO; the slopes shown covered 6,9 and 13 months of analysis, respectively. One point typically represents 20 injections of each standard.

Method application: SPE-CI-CSIA of spiked water samples and hydrolysis experiment. The newly developed GC-qMS method was applied to assess whether SPE of largevolume environmental water samples created isotope fractionation through analyses of agricultural drainage water samples spiked with the target herbicides and to validate the method over a wide range of $\mathrm{Cl}$ isotope signatures, generated by alkaline hydrolysis of METO.

Spiked large-volume water samples. To be able to apply ClCSIA to environmental water samples at concentrations equal to the threshold set by the EU Directive $98 / 83 / \mathrm{EC}(0.1 \mu \mathrm{g} / \mathrm{L}$ individual pesticide), a 50,000-fold pre-concentration (for a LPIA of $5 \mathrm{mg} / \mathrm{L}$ in the extract, after SPE) or a 100,000-fold preconcentration (for a LPIA of $10 \mathrm{mg} / \mathrm{L}$ ) is required. This means that $5 \mathrm{~L}$ to $10 \mathrm{~L}$ should be extracted for a final extract volume of $100 \mu \mathrm{L}$. 
Extraction of the $10 \mathrm{~L}$ drainage water samples at 0.5 to $5 \mu \mathrm{g} / \mathrm{L}$ of the target herbicides induced negligible chlorine isotope fractionation (Fig. 4). The trueness of the whole SPE-Cl-CSIA method $\left(\Delta \delta^{37} \mathrm{Cl}\right)$ was within a $\sigma_{\mathrm{m}}$ of $\pm 1.0 \%$, except for ACETO for one sample (Table S4, SI). For one sample, accurate $\delta^{37} \mathrm{C}$ ATR value was obtained even at a concentration below the instrumental LPIA of $0.05 \mathrm{nmol} \mathrm{Cl}$ on-column. The combination of this Cl-isotope method with large-volume $\mathrm{SPE}^{28}$ will enable determination of chlorine isotope ratios of target herbicides in environmental water samples.

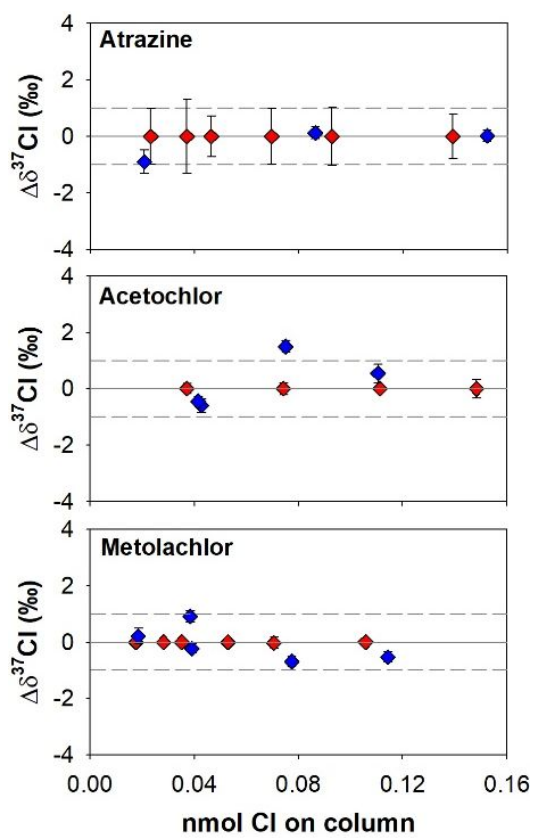

Figure 4. Method application: validation of the SPE-CSIA procedure for the determination of chlorine isotope ratios of ATR, ACETO and METO in 10-L drainage water samples (blue diamonds) spiked with 0.5 to $5 \mu \mathrm{g} / \mathrm{L}$ of ATR, ACETO and METO standards of known isotope signature. Error bars indicate total uncertainty $(n=10)$. Red diamonds represent the linearity test performed with the same standards (Fig. 2), with error bars indicating propagated $\sigma_{\mathrm{m}}$. The solid line represents $\Delta \delta^{37} \mathrm{Cl}=0 \%$ o while dashed lines represent the interval $\sigma_{\mathrm{m}}= \pm 1 \%$.

Hydrolysis experiment. Alkaline hydrolysis of METO resulted in pronounced shifts in $\delta^{37} \mathrm{Cl}(+46 \%)$ and $\delta^{13} \mathrm{C}(+17.3 \%)$ after $98 \%$ degradation (Fig. 5c), which correspond to a $\varepsilon_{\mathrm{Cl}}$ of $-9.7 \pm$ $2.9 \%$ (Fig. 5a) and a $\varepsilon_{\mathrm{C}}$ of $-3.3 \pm 1.0 \%$ (Fig. $5 \mathrm{~b}$; note that the fifth point was only considered for the dual plot: based on the predications of the median-based linear method on four points ${ }^{46-}$ ${ }^{48}$, the 5 th point was outside the confidence limits for $\mathrm{Cl}$ and $\mathrm{C}$ epsilon determination). Chlorine delta values uncorrected for two ${ }^{13} \mathrm{C}$ atoms are also shown in Figure S7 (SI) for comparison. The maximum difference between uncorrected and corrected $\delta^{37} \mathrm{Cl}$ value is $2.0 \%$ o for the fourth point $(19.4 \%$ ond $17.4 \%$, respectively). Nevertheless, this divergence resulted in similar $\varepsilon_{\mathrm{Cl}}$ within the uncertainty. This is the first study reporting $\mathrm{Cl}$ isotope enrichment during degradation of METO. This strong fractionation is promising for future environmental applications, as chlorine isotope fractionation might be a sensitive indicator of transformation processes even if the extent of degradation is limited. Indeed, applying the determined epsilon values, between 15 and $25 \%$ of the initial metolachlor has to be degraded to measure a $2 \%$ positive shift in chlorine isotope values, while 32 to $59 \%$ of the initial compound has to be degraded to measure the same positive shift in carbon isotope values. This information, in combination with carbon isotope data, may be useful for understanding hydrolytic reaction mechanisms, and establish a base to identify and quantify pesticide degradation mechanisms in the field, since there is a need to explore multi-element CSIA for defined pesticide degradation reactions under controlled laboratory conditions.
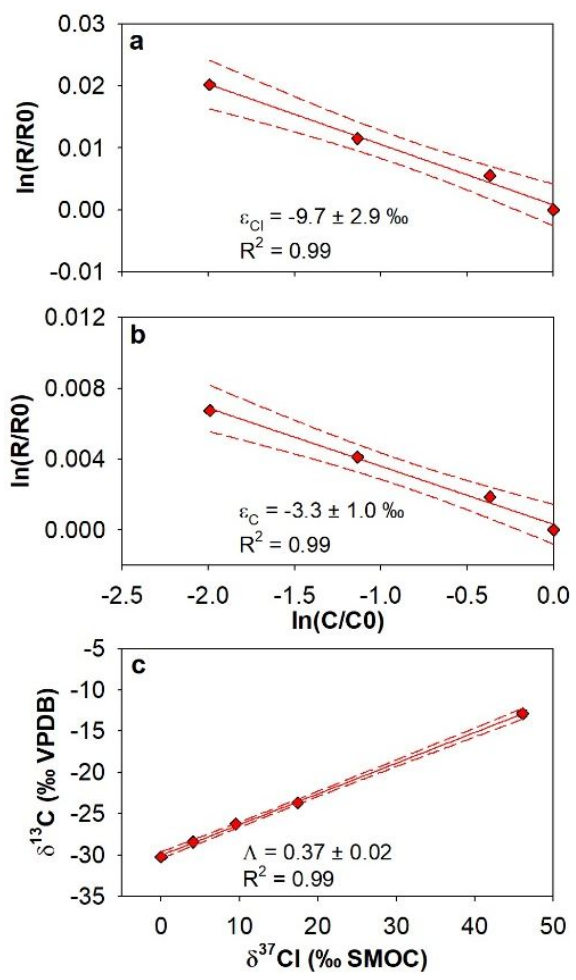

Figure 5. Method application: METO degradation by alkaline hydrolysis with logarithmic Rayleigh plots for a) chlorine and b) carbon; error bars display the uncertainty calculated by error propagation including uncertainties in concentration and isotope measurement (they may be smaller than symbols); c) dual $\mathrm{C}-\mathrm{Cl}$ plot; obtained slope $\left(\Lambda=\delta^{13} \mathrm{C} / \delta^{37} \mathrm{Cl}\right)$ is shown. Solid lines stand for the linear fitting curve and dashed lines for the associated $95 \%$ CI.

\section{Conclusions and outlook}

A method to analyze $\mathrm{Cl}$ isotope by $\mathrm{GC}$-qMS in the herbicides ATR, ACETO and METO, which are widespread water contaminants, has been successfully developed. The method allows accurate and precise Cl-CSIA in extracts in the $\mathrm{mg} / \mathrm{L}-$ concentration range: LPIAs of $10 \mathrm{mg} / \mathrm{L}$ for ATR and ACETO and $5 \mathrm{mg} / \mathrm{L}$ for METO with an associated uncertainty comprised between 0.5 and 1\%o. Furthermore, the method is accessible with a relatively simple and cheap setup, as a regular GC-qMS with a split/splitless injector is enough to perform analyses. The combination of this method with large-volume extraction ${ }^{28}$ allows chlorine isotope analysis of these herbicides in environmental water samples and opens new applications for CSIA. We validated the whole SPE-Cl-CSIA method in $10 \mathrm{~L}$ drainage water samples spiked with the target herbicides at environmental relevant concentrations $(0.5$ to $5 \mu \mathrm{g} / \mathrm{L})$. Multielement CSIA (e.g. carbon, nitrogen and chlorine) can now be used for assessing the fate of ATR, ACETO and METO in environmental water systems. For herbicides, and more 
generally micropollutants, very little is known about isotope fractionation associated with reaction mechanisms relevant for field studies. Hence, future studies are warranted to better understand how variable dual isotope slopes are for specific processes in order to identify them unequivocally in the field.

\section{ASSOCIATED CONTENT}

\section{Supporting Information}

Further details on target analytes, analytical and extraction methods, GC-qMS method performance and results of the validation tests are available in Supporting Information. The Supporting Information is available free of charge on the ACS Publications Website.

\section{AUTHOR INFORMATION}

\section{Corresponding Author}

*Phone: +1-514-987-3000 x3375; e-mail: ponsin.violaine@uqam.ca

\section{Present Addresses}

$\ddagger$ Present Address: Département des sciences de la Terre et de l'atmosphère, Université du Québec à Montréal, 201 avenue du Président Kennedy, Montréal, QC, Canada.

$\nmid$ Present Address: Grup MAiMA, Departament de Mineralogia, Petrologia i Geologia Aplicada, Facultat de Ciències de la Terra, Universitat de Barcelona (UB), C/ Martí i Franquès s/n, 08028, Barcelona, Spain.

\section{Author Contributions}

The manuscript was written through contributions of all authors. All authors have given approval to the final version of the manuscript.

\section{Notes}

The authors declare no competing financial interest.

\section{ACKNOWLEDGMENT}

This study was supported by the project CRSII2_141805/1 from the Swiss National Science Foundation (SNSF).

\section{REFERENCES}

(1) Loos, R.; Locoro, G.; Comero, S.; Contini, S.; Schwesig, D.; Werres, F.; Balsaa, P.; Gans, O.; Weiss, S.; Blaha, L.; et al. PanEuropean Survey on the Occurrence of Selected Polar Organic Persistent Pollutants in Ground Water. Water Res. 2010, 44 (14), 4115 4126.

(2) Fenner, K.; Canonica, S.; Wackett, L. P.; Elsner, M. Evaluating Pesticide Degradation in the Environment: Blind Spots and Emerging Opportunities. Science 2013, 341 (6147), 752-758.

(3) Lopez, B.; Ollivier, P.; Togola, A.; Baran, N.; Ghestem, J.-P. Screening of French Groundwater for Regulated and Emerging Contaminants. Sci. Total Environ. 2015, 518-519, 562-573.

(4) Elsner, M.; Hofstetter, T. B. Current Perspectives on the Mechanisms of Chlorohydrocarbon Degradation in Subsurface Environments: Insight from Kinetics, Product Formation, Probe Molecules, and Isotope Fractionation. In Aquatic Redox Chemistry; Tratnyek, P. G., Grundl, T. J., Haderlein, S. B., Eds.; American Chemical Society: Washington, DC, 2011.

(5) Masbou, J.; Drouin, G.; Payraudeau, S.; Imfeld, G. Carbon and Nitrogen Stable Isotope Fractionation during Abiotic Hydrolysis of Pesticides. Chemosphere 2018, 213, 368-376.

(6) Chevallier, M. L.; Cooper, M.; Kümmel, S.; Barbance, A.; Le Paslier, D.; Richnow, H. H.; Saaidi, P.-L.; Adrian, L. Distinct Carbon Isotope Fractionation Signatures during Biotic and Abiotic Reductive
Transformation of Chlordecone. Environ. Sci. Technol. 2018, 52 (6), $3615-3624$.

(7) Badea, S.-L.; Vogt, C.; Weber, S.; Danet, A.-F.; Richnow, H.-H. Stable Isotope Fractionation of $\gamma$-Hexachlorocyclohexane (Lindane) during Reductive Dechlorination by Two Strains of Sulfate-Reducing Bacteria. Environ. Sci. Technol. 2009, 43 (9), 3155-3161.

(8) Wu, L.; Yao, J.; Trebse, P.; Zhang, N.; Richnow, H. H. Compound Specific Isotope Analysis of Organophosphorus Pesticides. Chemosphere 2014, 111, 458-463.

(9) Meyer, A. H.; Penning, H.; Lowag, H.; Elsner, M. Precise and Accurate Compound Specific Car-bon and Nitrogen Isotope Analysis of Atrazine: Critical Role of Combustion Oven Conditions. Environ. Sci. Technol. 2008, 42 (21), 7757-7763.

(10) Cincinelli, A.; Pieri, F.; Zhang, Y.; Seed, M.; Jones, K. C. Compound Specific Isotope Analysis (CSIA) for Chlorine and Bromine: A Review of Techniques and Applications to Elucidate Environmental Sources and Processes. Environ. Pollut. 2012, 169, 112127.

(11) Heckel, B.; Rodríguez-Fernández, D.; Torrentó, C.; Meyer, A.; Palau, J.; Domènech, C.; Rosell, M.; Soler, A.; Hunkeler, D.; Elsner, M. Compound-Specific Chlorine Isotope Analysis of Tetrachloromethane and Trichloromethane by Gas ChromatographyIsotope Ratio Mass Spectrometry vs Gas Chromatography-Quadrupole Mass Spectrometry: Method Development and Evaluation of Precision and Trueness. Anal. Chem. 2017, 89 (6), 3411-3420.

(12) Shouakar-Stash, O.; Drimmie, R. J.; Zhang, M.; Frape, S. K. Compound-Specific Chlorine Isotope Ratios of TCE, PCE and DCE Isomers by Direct Injection Using CF-IRMS. Appl. Geochem. 2006, 21 (5), 766-781.

(13) Reddy, C. M.; Drenzek, N. J.; Eglinton, T. I.; Heraty, L. J.; Sturchio, N. C.; Shiner, V. J. Stable Chlorine Intramolecular Kinetic Isotope Effects from the Abiotic Dehydrochlorination of DDT. Environ. Sci. Pollut. Res. 2002, 9 (3), 183-186.

(14) Drenzek, N. J.; Tarr, C. H.; Eglinton, T. I.; Heraty, L. J.; Sturchio, N. C.; Shiner, V. J.; Reddy, C. M. Stable Chlorine and Carbon Isotopic Compositions of Selected Semi-Volatile Organochlorine Compounds. Org. Geochem. 2002, 33 (4), 437-444.

(15) Gilevska, T.; Ivdra, N.; Bonifacie, M.; Richnow, H.-H. Improvement of Analytical Method for Chlorine Dual-Inlet Isotope Ratio Mass Spectrometry of Organochlorines. Rapid Commun. Mass Spectrom. 2015, 29 (14), 1343-1350.

(16) Ivdra, N.; Fischer, A.; Herrero-Martin, S.; Giunta, T.; Bonifacie, M.; Richnow, H.-H. Carbon, Hydrogen and Chlorine Stable Isotope Fingerprinting for Forensic Investigations of Hexachlorocyclohexanes. Environ. Sci. Technol. 2017, 51 (1), 446454.

(17) Annable, W. K.; Frape, S. K.; Shouakar-Stash, O.; Shanoff, T.; Drimmie, R. J.; Harvey, F. E. 37Cl, 15N, 13C Isotopic Analysis of Common Agro-Chemicals for Identifying Non-Point Source Agricultural Contaminants. Appl. Geochem. 2007, 22 (7), 1530-1536.

(18) Holmstrand, H.; Andersson, P.; Gustafsson, Ö. Chlorine Isotope Analysis of Submicromole Organochlorine Samples by Sealed Tube Combustion and Thermal Ionization Mass Spectrometry. Anal. Chem. 2004, 76 (8), 2336-2342.

(19) Grzybkowska, A.; Kaminski, R.; Dybala-Defratyka, A. Theoretical Predictions of Isotope Effects versus Their Experimental Values for an Example of Uncatalyzed Hydrolysis of Atrazine. Phys. Chem. Chem. Phys. 2014, 16 (29), 15164-15172.

(20) Renpenning, J.; Horst, A.; Schmidt, M.; Gehre, M. J. Online Isotope Analysis of $37 \mathrm{Cl} / 35 \mathrm{Cl}$ Universally Applied for Semi-Volatile Organic Compounds Using GC-MC-ICPMS. Anal. At. Spectrom. 2018, 33 (2), 314-321.

(21) Lihl, C., Renpenning, J., Kümmel, S.; Gelman, F., Schürner, H.K.V., Daubmeier, M., Heckel, B., Melsbach, A., Bernstein, A., Shouakar-Stash, O., Gehre, M., Elsner, M. Toward Improved Accuracy in Chlorine Isotope Analysis: Synthesis Routes for In-House Standards and Characterization via Complementary Mass Spectrometry Methods. Anal. Chem. 2019, 91, (19), 12290-12297.

(22) Torgonskaya, M. L.; Zyakun, A. M.; Trotsenko, Y. A.; Laurinavichius, K. S.; Kümmel, S.; Vuilleumier, S.; Richnow, H. H. Individual Stages of Bacterial Dichloromethane Degradation Mapped 
by Carbon and Chlorine Stable Isotope Analysis. J. Environ. Sci. 2019, $78,147-160$.

(23) Sakaguchi-Söder, K.; Jager, J.; Grund, H.; Matthäus, F.; Schüth, C. Monitoring and Evaluation of Dechlorination Processes Using Compound-Specific Chlorine Isotope Analysis. Rapid Commun. Mass Spectrom. 2007, 21 (18), 3077-3084.

(24) Sakaguchi-Söder, K. A new method for compound-specific stable chlorine isotope analysis: basics and application. Schriftenreihe IWAR; Inst. IWAR: Darmstadt, 2010.

(25) Aeppli, C.; Holmstrand, H.; Andersson, P.; Gustafsson, Ö. Direct Compound-Specific Stable Chlorine Isotope Analysis of Organic Compounds with Quadrupole GC/MS Using Standard Isotope Bracketing. Anal. Chem. 2010, 82 (1), 420-426.

(26) Bernstein, A.; Shouakar-Stash, O.; Ebert, K.; Laskov, C.; Hunkeler, D.; Jeannottat, S.; Sakaguchi-Söder, K.; Laaks, J.; Jochmann, M. A.; Cretnik, S.; et al. Compound-Specific Chlorine Isotope Analysis: A Comparison of Gas Chromatography/Isotope Ratio Mass Spectrometry and Gas Chromatography/Quadrupole Mass Spectrometry Methods in an Interlaboratory Study. Anal. Chem. 2011, 83 (20), 7624-7634.

(27) Ebert, K. A.; Laskov, C.; Elsner, M.; Haderlein, S. B. Calibration Bias of Experimentally Determined Chlorine Isotope Enrichment Factors: The Need for a Two-Point Calibration in Compound-Specific Chlorine Isotope Analysis: Two-Point Calibration in Compound-Specific Chlorine Isotope Analysis. Rapid Commun. Mass Spectrom. 2017, 31 (1), 68-74.

(28) Torrentó, C.; Bakkour, R.; Glauser, G.; Melsbach, A.; Ponsin; Hofstetter, T. B.; Elsner, M.; Hunkeler, D. Solid-Phase Extraction Method for Stable Isotope Analysis of Pesticides from Large Volume Environmental Water Samples. Analyst 2019, 144, 2898-2908.

(29) Muthmann, R. The Use of Plant Protection Products in the European Union. In Eurostat Statistical Books; Environment and energy; Office for Official Publications of the European Communities: Luxembourg, 2007.

(30) Pesticides Sales - Environmental Indicator Report 2018; European Environment Agency: Copenhagen, 2018.

(31) Atwood, D.; Paisley-Jones, C. Pesticides Industry Sales and Usage - 2008-2012 Market Estimates; U.S. Environmental Protection Agency: Washington, 2017.

(32) Sousa, J. C. G.; Ribeiro, A. R.; Barbosa, M. O.; Pereira, M. F. R.; Silva, A. M. T. A Review on Environmental Monitoring of Water Organic Pollutants Identified by EU Guidelines. J. Hazard. Mater. 2018, 344, 146-162.

(33) Postigo, C.; Barceló, D. Synthetic Organic Compounds and Their Transformation Products in Groundwater: Occurrence, Fate and Mitigation. Sci. Total Environ. 2015, 503-504, 32-47.

(34) Elsner, M.; Hunkeler, D. Evaluating Chlorine Isotope Effects from Isotope Ratios and Mass Spectra of Polychlorinated Molecules. Anal. Chem. 2008, 80 (12), 4731-4740.

(35) Jin, B.; Laskov, C.; Rolle, M.; Haderlein, S. B. Chlorine Isotope Analysis of Organic Contaminants Using GC-QMS: Method Optimization and Comparison of Different Evaluation Schemes. Environ. Sci. Technol. 2011, 45 (12), 5279-5286.
(36) Horst, A.; Renpenning, J.; Richnow, H.-H.; Gehre, M. Compound Specific Stable Chlorine Isotopic Analysis of Volatile Aliphatic Compounds Using Gas Chromatography Hyphenated with Multiple Collector Inductively Coupled Plasma Mass Spectrometry. Anal. Chem. 2017, 89 (17), 9131-9138.

(37) Jochmann, M. A.; Blessing, M.; Haderlein, S. B.; Schmidt, T. C. A New Approach to Determine Method Detection Limits for Compound-Specific Isotope Analysis of Volatile Organic Compounds. Rapid Commun. Mass Spectrom. 2006, 20 (24), 3639-3648.

(38) Rayleigh, L. Theoretical Considerations Respecting the Separation of Gases by Diffusion and Similar Processes. Lond. Edinb. Dublin Philos. Mag. J. Sci. 1896, 42 (259), 493-498.

(39) Elsayed, O. F.; Maillard, E.; Vuilleumier, S.; Nijenhuis, I.; Richnow, H. H.; Imfeld, G. Using Compound-Specific Isotope Analysis to Assess the Degradation of Chloroacetanilide Herbicides in Lab-Scale Wetlands. Chemosphere 2014, 99, 89-95.

(40) Chen, S.; Yang, P.; Rohit kumar, J.; Liu, Y.; Ma, L. Inconsistent Carbon and Nitrogen Isotope Fractionation in the Biotransformation of Atrazine by Ensifer Sp. CX-T and Sinorihizobium Sp. K. Int. Biodeterior. Biodegrad. 2017, 125, 170-176.

(41) Ehrl, B. N.; Gharasoo, M.; Elsner, M. Isotope Fractionation Pinpoints Membrane Permeability as a Barrier to Atrazine Biodegradation in Gram-Negative Polaromonas Sp. Nea-C. Environ. Sci. Technol. 2018, 52 (7), 4137-4144.

(42) Meyer, A. H.; Penning, H.; Elsner, M. C and N Isotope Fractionation Suggests Similar Mechanisms of Microbial Atrazine Transformation Despite Involvement of Different Enzymes (AtzA and TrzN). Environ. Sci. Technol. 2009, 43 (21), 8079-8085.

(43) Schürner, H. K. V.; Seffernick, J. L.; Grzybkowska, A.; DybalaDefratyka, A.; Wackett, L. P.; Elsner, M. Characteristic Isotope Fractionation Patterns in S-Triazine Degradation Have Their Origin in Multiple Protonation Options in the s-Triazine Hydrolase TrzN. Environ. Sci. Technol. 2015, 49 (6), 3490-3498.

(44) Meyer, A. H.; Dybala-Defratyka, A.; Alaimo, P. J.; Geronimo, I.; Sanchez, A. D.; Cramer, C. J.; Elsner, M. Cytochrome P450Catalyzed Dealkylation of Atrazine by Rhodococcus Sp. Strain NI86/21 In-volves Hydrogen Atom Transfer Rather than Single Electron Transfer. Dalton Trans. 2014, 43 (32), 12175-12186.

(45) Alvarez-Zaldívar, P.; Payraudeau, S.; Meite, F.; Masbou, J.; Imfeld, G. Pesticide Degradation and Export Losses at the Catchment Scale: Insights from Compound-Specific Isotope Analysis (CSIA). Water Res. 2018, 139, 198-207

(46) Sen, P.K. Estimates of Regression Coefficient Based on Kendall's tau. J. Am. Stat. Ass., 1968, 63, 1379-1389.

(47) Siegel, A.F. Robust Regression Using Repeated Medians. Biometrika, 1982, 69, 242-244

(48) Komsta, L. mblm: Median-Based Linear Models. R package version $0.12 .1,2019$, https://CRAN.R-project.org/package $=$ mblm

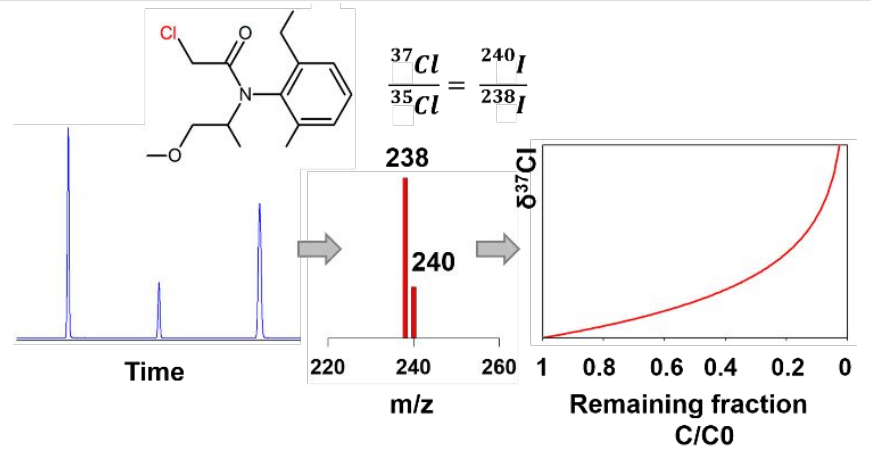

